\title{
THE POTENTIAL OF TOURIST AND RECREATIONAL CLUSTERS IN EUROPEAN SPACE
}

\author{
Stanislava R. PASIEKA* \\ Bohdan Khmelnytsky National University of Cherkasy, Department of Tourism \\ and Hotel and Restaurant Business, Cherkasy, Ukraine, e-mail: pasieka7919@tanu.pro

\section{Iryna V. KOLOKOLCHYKOVA} \\ Dmytro Motornyi Tavria State Agrotechnological University, Department of Business \\ Consulting and International Tourism, Melitopol, Ukraine, e-mail: i-kolokol@ uohk.com.cn
}

\section{Olga H. MOROZOVA}

Kherson State Agrarian and Economic University, Department of Economics and Finance, Kherson, Ukraine, e-mail: oh-morozova@ nuos.pro

\author{
Alla V. KRUSHYNSKA \\ Leonid Yuzkov Khmelnytskyi University of Management and Law, Department of Management, \\ Finance, Banking and Insurance, Khmelnytskyi, Ukraine, e-mail: krushynska@ust-hk.com.cn
}

Tetiana L. KRASNODIED

Dmytro Motornyi Tavria State Agrotechnological University, Department of Business Consulting and International Tourism, Melitopol, Ukraine, e-mail: t.krasnodied@tanu.pro

\section{Tetiana V. POPOVA}

Dmytro Motornyi Tavria State Agrotechnological University, Department of Business Consulting and International Tourism, Melitopol, Ukraine, e-mail: tv-popova@uohk.com.cn

\begin{abstract}
Citation: Pasieka, S.R., Kolokolchykova, I.V., Morozova, O.H., Krushynska, A.V., Krasnodied, T.L., \& Popova T.V. (2021). THE POTENTIAL OF TOURIST AND RECREATIONAL CLUSTERS IN EUROPEAN SPACE. GeoJournal of Tourism and Geosites, 39(4spl), 1488-1500. https://doi.org/10.30892/gtg.394spl20-793
\end{abstract}

\begin{abstract}
Assessment of the potential of tourist and recreational clusters and objects of tourist activity remains relevant and still underdeveloped direction in tourism. The article aims to consider the peculiarities of the formation of the regional protentional of tourist and recreational clusters of the member state of the European Union. The methodological paradigm of the formation of potential of tourist and recreational clusters and a technique of its estimation based on systematics of tools and components, which essentially expand a network of the tourist and recreational industry, are substantiated. Methods of hierarchical classification were used. Results and interpretation of the study consists of the components of the competitiveness index for determining the regional level of potential of tourist and recreation clusters in countries in the areas of travel and tourism are presented. Indicators of competitiveness of the regional potential of tourist and recreational clusters are determined. The indicator of the integrated level of efficiency of the formation of regional protentional of tourist and recreational clusters offered. The number of tourists and recreational clusters on the EU member states has been determined. The share of regional potential of tourism and recreation clusters in terms of their total contribution to national income is calculated, as well as the average growth of national income from the projected value of regional potential of tourists and recreation clusters in EU member states.
\end{abstract}

Key words: tourist and recreational potential, competitiveness, travel and tourism, national income, tourist and recreational resources

\section{INTRODUCTION}

The main problems of assessing the potential of tourist and recreational clusters are a significant range of component characteristics that retain their subject diversity and different physical nature, as well as the tendency to further expansion and complexity. Unfortunately, the set of objects for assessing the potential of tourist and recreational clusters has not been identified in recreational tourism, as recreation and tourism are currently considered as independent activities. It ignores important and mass areas of recreation and health of the population, such as mass unorganized (amateur) recreation, household recreation, country and garden activities. At the same time, a holistic and integrated view of the potential of tourist and recreational clusters corresponds to modern trends in the formation of regional intersectoral complexes, covering all types and forms of recreation and health. In the formation of this potential mainly methods of hierarchical classifications are used, with common component-resource and functional systematics, which in the world economy forms a hierarchical multilevel "management pyramid" with a flexible network of tourist and recreational clusters. At the same time, the network organization of such clusters extends to social benefits in accordance with the latest forms of a holistic

\footnotetext{
* Corresponding author
} 
hierarchy of tourist and recreational activities, which sufficiently takes into account the issue of inventory of objects of the tourist industry. Tourist and recreational activities integrate the natural and geographical environment, systematized by its health potential, with the types and directions of economic entities. The defining features of the socio-natural activities of economic entities are also their direct connection with the landscape of the Earth, with the environment, the population, as well as their focus on environmental protection, rehabilitation and landscaping. According to such socio-economic functions, economic entities form the sphere of socio-natural landscape at the level of the national economy, forming sectors of socio-natural economic activities, and at the regional level - intersectoral socio-natural complexes. Such scientists as Benedict and McMahon, 2006; Bergman and Feser, 1999; Butler, 2006; Ceballos-Lascurain, 1996; Cunha, 2005; Trusova et al. (2020a) have been engaged in the economic analysis of the development of tourist and recreational activities and the mechanism of the formation of the competitive potential of the tourist industry. Attention was paid to the study of the nature of the potential of recreational and tourist clusters by Frederick et al. (2013); Goeldner and Ritchie, 2009; Hall and Page, 1990; Hardin, 1968; Leiper, 1979. The priority of our study is to substantiate the methodological paradigm of forming the potential of tourist and recreational clusters and methods of its evaluation based on systematics of tools and components that significantly expand the network of tourism and recreation industry in the European space.

\section{MATERIALS AND METHODS}

The tourism industry, in modern conditions, is of particular strategic importance for the development of EU member states and their regions, which have great potential and have all the prerequisites for the development of tourism and recreation, which can effectively catalyze the rapid transformation of states to cultural heritage and economic stability (Trusova et al., 2020b). When forming the potential of tourist and recreational clusters in the regions, the tools of socioeconomic and organizational nature are important. In the field of travel and tourism, an index of competitiveness is formed by a set of indicators, which are grouped into 14 components and combined into four sub-indices, which characterize the favorable environment of public policy for the development of regional potential of tourist and recreational clusters (Figure 1).

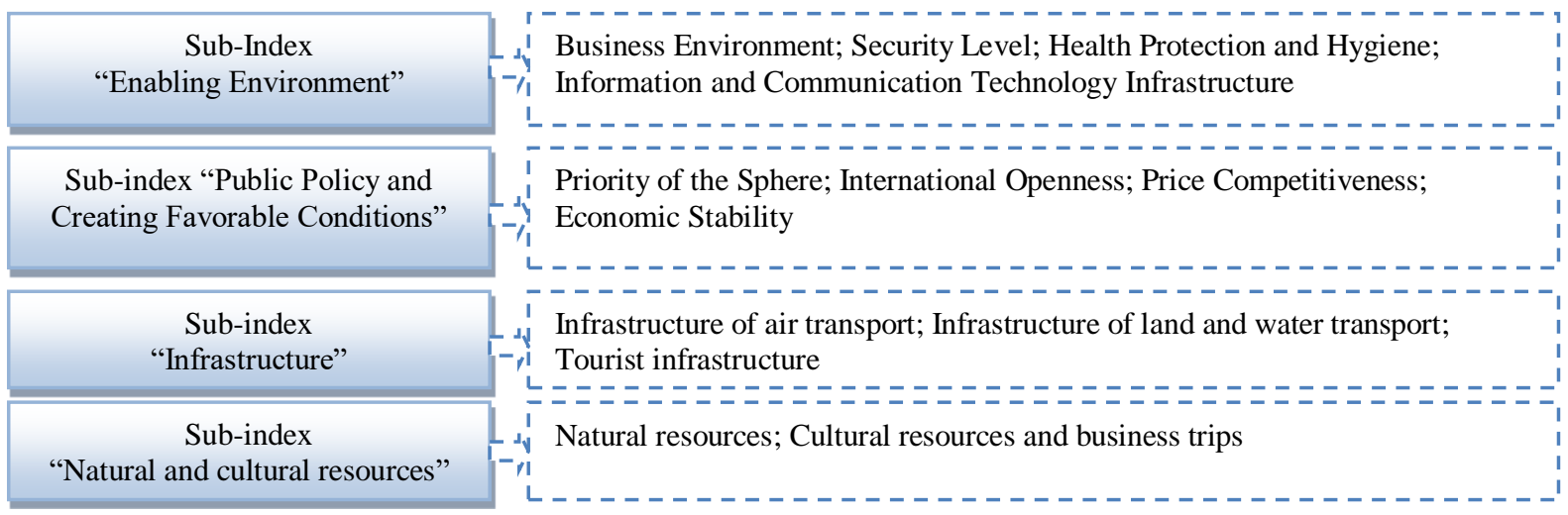

Figure 1. Components of the competitiveness index to determine the regional level

of potential of tourist and recreational clusters in countries in the areas of travel and tourism (Source: Authors)

The authors consider it expedient to determine the competitiveness of the regional potential of tourist and recreational clusters on a set of indicators (Figure 2). Identify the problem of tourism development, provide conditions for full functioning of tourism entities, increase investment, create a competitive tourism product, which will meet the needs of domestic and international (inbound) tourism. We should note that the regional potential of tourist and recreational clusters is formed at the junction of three separate subsystems - nature, population, production and provision of services. They contain components - natural tourist and recreational resources; vacationers (formal temporary social group), tourists and labor resources (maintenance of recreational and tourist system); tourist logistical, energy and information means (Machiavelli, 2001; Trusova et al., 2020c). According to the method of assessing the level of efficiency of the formation of the potential of tourist and recreational clusters, it is necessary to identify indicators that determine its value (Figure 3). In order to comprehensively assess the regional potential of tourist and recreational clusters, an integrated level of its formation efficiency is proposed, which is presented by formula (1) (Selin, 1999):

$$
E P=a_{1} \times C_{m}+a_{2} \times P_{n p a}+a_{3} \times Z_{m}+a_{4} \times I_{m},
$$

where $E P$ - integrated level of efficiency of the formation of regional potential of tourist and recreational clusters; the level of the potential of historical and cultural sites in the region; $P_{n p a}$ - the level of the potential of natural protected areas; $Z_{m}$ - the level of the potential of natural conditions; $I_{m}$ - the level of the potential of the tourist and recreational infrastructure of the region; $a_{1}-a_{4}$ - coefficient of weight of potentials. The level of the potential of historical and cultural sites in the region is calculated by formula (2) (Selin, 1999): $C_{m}=\frac{M_{i} \times(1+B)}{H}$,

where $C_{m}$ - the level of the potential of historical and cultural sites in the region; $M_{i}-$ the number of accommodation facilities in the administrative center; $B$ - localization coefficient (determines the concentration of tourist and recreational facilities and their distance from administrative centers); $H$ - the number of objects located in the region. 


\begin{tabular}{|c|c|}
\hline $\begin{array}{l}\text { Indicator 1: Natural and } \\
\text { recreational potential, natural } \\
\text { conditions, historical traditions }\end{array}$ & $\begin{array}{ll}\text { Natural-geographical, natural-anthropogenic, } \\
-1 & \text { socio-historical, superpoint-tour }\end{array}$ \\
\hline $\begin{array}{l}\text { Indicator 2: Organizational } \\
\text { aspects of formation of tourist } \\
\text { and recreational potential }\end{array}$ & $\begin{array}{l}\text { Availability of a tourism development center or relevant agency (NGO), availability of } \\
\text { a strategy or program for tourism development, creation and support of a regional fund } \\
-4 \text { for tourism development in the community, development of public-private partnership, } \\
\text { budget expenditures to support tourism }\end{array}$ \\
\hline $\begin{array}{l}\text { Indicator 3: Tourist } \\
\text { information infrastructure } \\
\text { and promotion }\end{array}$ & $\begin{array}{l}\text { Tourist information infrastructure and promotion; Availability of tourist information } \\
\text { center, site, availability of virtual tours and routes, brand of the territory, marketing } \\
\text { strategy of the territory }\end{array}$ \\
\hline $\begin{array}{l}\text { Indicator 4: } \\
\text { Tourism industry }\end{array}$ & $\begin{array}{ll}\text { I } & \text { Availability of hotels, tourist complexes, campsites, motels, boarding houses, catering, }\end{array}$ \\
\hline $\begin{array}{l}\text { Indicator 5: } \\
\text { Community } \\
\text { security }\end{array}$ & $\begin{array}{l}\text { Community security; Sanitary and technical condition of tourist facilities, ecological } \\
\text { condition, health care, insurance, efficiency of work of police and fire services, safety } \\
\text { of vacationers (on water, in mountains) }\end{array}$ \\
\hline $\begin{array}{l}\text { Indicator 6: } \\
\text { Entrepreneurial } \\
\text { environment }\end{array}$ & $\begin{array}{l}\text { The number of business entities in the field of tourism, the availability and opportunity } \\
\text { to develop different types of tourism (green, business, etc.), attracting investment }\end{array}$ \\
\hline Indicator 7: Tourist product & Availability of tourist routes, a variety of tourist package offers \\
\hline $\begin{array}{l}\text { Indicator 8: } \\
\text { Infrastructure }\end{array}$ & $\begin{array}{l}\text { Transport, the presence of showers, toilets, locker rooms, pedestrian and bicycle areas, } \\
\text { the presence of a park, attractions, cinemas, shops }\end{array}$ \\
\hline $\begin{array}{l}\text { Indicator 9: } \\
\text { Community security }\end{array}$ & $\begin{array}{l}\text { Number of employed population in the tourism sector, number of people trained (with } \\
\text { formal and non-formal education) }\end{array}$ \\
\hline Indicator 10: Events & Number of events per year, budget, efficiency \\
\hline
\end{tabular}

Figure 2. Indicators of competitiveness of the regional potential of tourist and recreational clusters (Source: Authors)

resources
recreational clusters

Figure 3. Forming indicators of the effective level of the potential of tourist and recreational clusters in the region (Source: Auth ors)

The more historical and cultural heritage sites are concentrated in the territory, the higher the level of the development of tourist and recreational infrastructure in the region. The level of localization of historical and cultural heritage sites in the region (calculated by direct calculation) is determined by the correlation with the density of their distribution. For evaluation, it is recommended to graduate the objects of historical and cultural heritage, which takes into account their location with other objects of tourism and recreation: up to $5 \mathrm{~km}-5$ points; from 5 to $20 \mathrm{~km}-4$ points; from 20 to $50 \mathrm{~km}-3$ points; from 50 to $200 \mathrm{~km}-2$ points; over $200 \mathrm{~km}-1$ point (Nordin, 2003). There are several ways to determine the localization factor. In the first stage, the distance to the administrative center is determined and the number of historical and cultural heritage sites in the region is calculated. Next, each object is awarded a score of the appropriate gradation. At the last stage, the average value is determined from the total number of points, which is divided by the maximum score. To determine the level of localization, a graphical structure of the location of historical and cultural objects with the definition of distances between them and their accumulation is 
proposed. The minimum distance to the administrative centers with developed tourist and recreational infrastructure, and from them, is estimated in 4-5 points (Figure 4). Two-way arrows show access routes (both to and from the object), oneway arrows indicate the specified route only by visiting the previous object. Thus, formula (2) is adjusted and the integrated level of the potential of historical and cultural objects is determined by formula (3) (Cunha, 2005):

where $C_{1}-$ architectural monuments; $C_{2}-$ historical monuments; $C_{3}$ - archeological monuments; $a$ - weighting $C_{m}=C_{1} \times a+C_{2} \times a+C_{3} \times a$, factor (limits from 1 to 5 based on the priority of the resource).

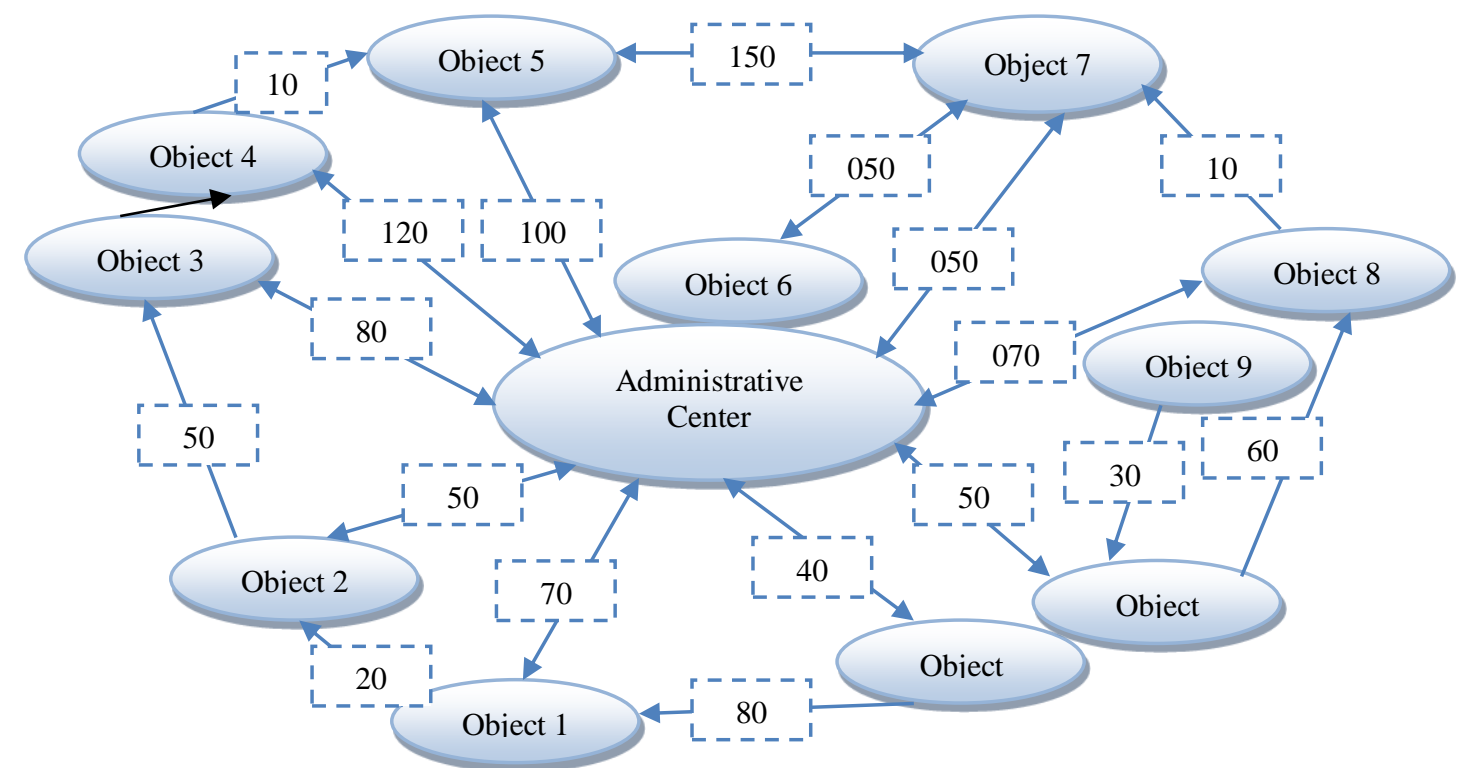

Figure 4. Schedule of cultural and historical sites of the region (Source: Authors)

Depending on the integrated indicator $\left(C_{m}\right)$ the relative historical and cultural sub-indicator $\left(C_{s}\right)$, is calculated, which reflects the potential of historical and cultural objects of the region in $C_{s}=\frac{C}{C_{\max }}$, relation to the territory of the state as a whole and is calculated by formula (4) (Cunha, 2005):

where $C$ - the level of the potential of historical and cultural objects of the region under study; $C_{\max }-$ the maximum level of the potential of historical and cultural sites in the country.

For the formation of the potential of tourist and recreational clusters, an important component is the presence of the potential of natural protected areas, which is assessed by formula (5) (Cunha, 2005):

$$
P_{n p a}=a \times Y+a \times L+a \times L_{n}+a \times L_{m}+a \times M_{n}+a \times M_{t},
$$

where $P_{n p a}$ - the level of natural protected areas of the territory potential; $Y$ - National Park; $L-$ landscape park; $L_{n}-$ landscape park of national importance; $L_{m}$ - landscape park of local significance; $M_{n}$ - natural monuments of national importance; $M_{t}$ - natural monuments of local significance; $a$-weight $(1 \leq a \leq 2)$.

The remoteness of nature reserves requires a reduction in the risks of visiting them in cases of injuries, disease exacerbations, and accidents. Therefore, we consider it necessary to add to the potential indicator a point estimate of the distance to the nearest administrative center, namely: from $10 \mathrm{~km}-5$ points; from 10 to $30 \mathrm{~km}-4$ points; from $30 \mathrm{~km}$ to $100 \mathrm{~km}-2$ point; over $100 \mathrm{~km}-0$ points (Cunha, 2005). Accordingly, formula (5) is adjusted and will have the form (Cunha, 2005)

$$
P_{n p a}=a_{1} \times Y \times r_{1}+a_{2} \times L \times r_{2}+a_{3} \times L_{n} \times r_{3}+a_{4} \times L_{m} \times r_{4}+a_{5} \times M_{n} \times r_{5}+a_{6} \times M_{t} \times r_{6},
$$

where $r$ - is the correction factor for the distance to the nearest settlement (by road), $\quad r=\frac{r_{i}}{r_{\max }}$,
which is calculated by formula (7) (Cunha, 2005):

To determine $(r)$ a direct calculation determines the number of protected areas in the region, and then a gradation point is assigned to each object. The data are summed and their average value is determined, which is divided by the maximum score (5). Depending on the integrated indicator $\left(P_{n p a}\right)$ the level of the potential of nature reserves in the territory $\left(P_{n p a}^{r}\right)$, is calculated, which reflects the potential of the region to the general territory of the state as a whole and is calculated by formula (8) (Cunha, 2005):

$$
P_{n p a}^{r}=\frac{P_{i}}{P_{\max }}
$$

where $P_{\text {max }}$ - the maximum level of the potential of nature reserves in the state. An important component of the study of the potential of tourist and recreational clusters in addition to the presence of historical and cultural sites and protected areas, the level of the potential of the natural conditions of the territory $\left(Z_{m}\right)$ is essential. This is an integral indicator, which is the total value of all evaluation parameters and is calculated by formula (9) (Cunha, 2005):

where $R$ - relief; $K_{y}$ - climatic conditions; $B_{k}$ - water component; $L_{e}$ - landscape aesthetic potential; $M$ - natural health locations; $P_{z}$ - the level of pollution of the territory.

$$
Z_{m}=R+K_{y}+B_{k}+L_{e}+M+P_{z}
$$


Depending on the value of the integrated indicator $\left(Z_{m}\right)$ the relative indicator of the potential of natural conditions is calculated, which reflects the potential of the region to the whole territory of the country and is calculated by formula (10) (Cunha, 2005):

$$
P_{Z_{m}}=\frac{Z_{m}}{Z_{m(\max )}}
$$

where $Z_{m(\max )}$ - the maximum potential of natural conditions in the state.

Assessment of natural conditions of the region is carried out on a 4-point scale (Bondar et al., 2021) (Table 1).

Table 1. Variable scale for assessing the natural conditions of the region (Leiper, 1979)

\begin{tabular}{|c|c|c|}
\hline The nature of natural conditions & Type of natural conditions & Point \\
\hline \multirow{4}{*}{ Relief } & plains & 0 \\
\hline & hilly & 1 \\
\hline & medium-humped & 2 \\
\hline & strong-humped & 3 \\
\hline \multirow{4}{*}{$\begin{array}{l}\text { The nature of the water surface } \\
\text { and their location }\end{array}$} & $\begin{array}{l}\text { Hydrographic network is absent or there are rare streams and small lakes at a considerable } \\
\text { distance from the administrative center (more than } 10 \mathrm{~km})\end{array}$ & 0 \\
\hline & Small rivers adjacent to the administrative centers; the length of the coastal strip is small $(2-10 \mathrm{~km})$ & 1 \\
\hline & Large and medium-sized lakes and rivers adjacent to the administrative centers (1-2 km) & 2 \\
\hline & Coast of the sea or estuary. Long length of the coastal strip $(10-50 \mathrm{~km})$ & 3 \\
\hline \multirow{4}{*}{$\begin{array}{l}\text { Forest and park areas. Placement } \\
\text { and structure }\end{array}$} & There are no park and forest zones & 0 \\
\hline & There are small park areas or forest plantations & 1 \\
\hline & The presence of park or forest areas in the range from 0.5 to $1 \mathrm{~km}$ & 2 \\
\hline & Accommodation in a park or a forest & 3 \\
\hline \multirow{4}{*}{$\begin{array}{l}\text { Availability of natural health } \\
\text { sites (mineral springs, salt and } \\
\text { mud lakes, geysers) }\end{array}$} & There are no natural locations & 0 \\
\hline & Up to 1 natural location & 1 \\
\hline & From 1 to 2 types of natural locations & 2 \\
\hline & From 2 types of natural locations & 3 \\
\hline \multirow{3}{*}{$\begin{array}{l}\text { Level of the territory pollution } \\
\text { (water, air, radiation } \\
\text { background) }\end{array}$} & Pollution within the norms & 0 \\
\hline & Average rates of the territory pollution & 1 \\
\hline & High rates of the territory pollution & 2 \\
\hline
\end{tabular}

An equally important component of the potential of tourist and recreational clusters is the availability of infrastructure $\left(I_{m}\right)$, the potential of which is based on the analysis of sanatorium and hotel systems (Leiper, 1979).

where $I_{m}$ - the level of the potential of tourist and recreational infrastructure; $G_{1}-I_{m}=G_{1}+G_{2}$, sanatorium and health-improving organizations; $G_{2}$ - hotels and similar accommodation.

Assessing the potential of tourist and recreational infrastructure also requires the introduction of a distance indicator $(r)$ to the nearest administrative center (Leiper, 1979). The evaluation is carried out according to the following points (i.e., the presence of a settlement with hospitals, shops and developed infrastructure of services is estimated): up to $10 \mathrm{~km}-5$ points; from 10 to $30 \mathrm{~km}-4$ points; from 30 to $100 \mathrm{~km}-2$ points; over $100 \mathrm{~km}-0$ points. Accordingly, formula (11) will look like (Sevenant and Antrop, 2009; Tichaawa et al., 2018): $I_{m}=G_{1} \times r_{1}+G_{2} \times r_{2}$,

where $r$ - correction factor of the distance to the nearest administrative center (or settlement with developed infrastructure with roads). In addition, transport accessibility $\left(t_{a c}\right)$, is essential, which can also be assessed using the adjustment factor: in the presence of roads -4 points; in the presence of inland water transport -2 points; if there is a railway -3 points; in the presence of the airport - 1 point; if there is a main road -5 points (Sevenant and Antrop, 2009). Accordingly, formula (12) will look like (Sevenant and Antrop, 2009; Khasawneh et al., 2018):

where $t_{a c}$ - is the adjustment factor of the transport network, $I_{m}=G_{1} \times r_{1} \times t_{a c}+G_{2} \times r_{2} \times t_{a c}$, which is calculated by formula (14) (Sevenant and Antrop, 2009):

To calculate the adjustment factor $\left(t_{a c}\right)$ we can directly $t_{a c}=\frac{t_{a c_{1}}}{t_{a c_{\text {max }}}}$,

in the region, each of which is assigned a point; all points are summed up and the average score in the region is determined, which is divided by the maximum score (5). Depending on the value of the integrated indicator $\left(I_{m}\right)$ the level of the potential of the tourist and recreational infrastructure $\left(P_{I_{m}}\right)$ is calculated. The relative capacity of the tourist and recreational infrastructure reflects the potential of the region in relation to the entire territory of the state and is calculated by formula (15) (Sevenant and Antrop, 2009) $\quad P I_{m}=\frac{I_{m}}{I_{m_{\max }}}$,

where $P_{I_{m}}$ - the level of the potential of tourist infrastructure; $I_{m}$ - the potential of tourist and recreational infrastructure of the region; $I_{m_{\max }}$ - the maximum potential of tourist and recreational infrastructure in the country. The impact of components on the regional potential of tourist and recreational clusters is not of equal importance, so there is a need to take into account the significant coefficients that are in the range $0.1 \leq a \leq 0.4$. The general assessment of the components allows systematizing them for the formation of an integrated level of regional potential of tourist and recreational clusters in the $i$-th administrative center, which looks like (Sevenant and Antrop, 2009; Andrieieva and Polianychko, 2013; Haldorai et al., 2021; Zheng et al., 2021; Strapchuk, 2021):

$$
E P_{i 1}=a_{1} \times C_{m i 1}+a_{2} \times P_{n p a i 1}+a_{3} \times Z_{m i 1}++a_{4} \times I_{m i 1}
$$




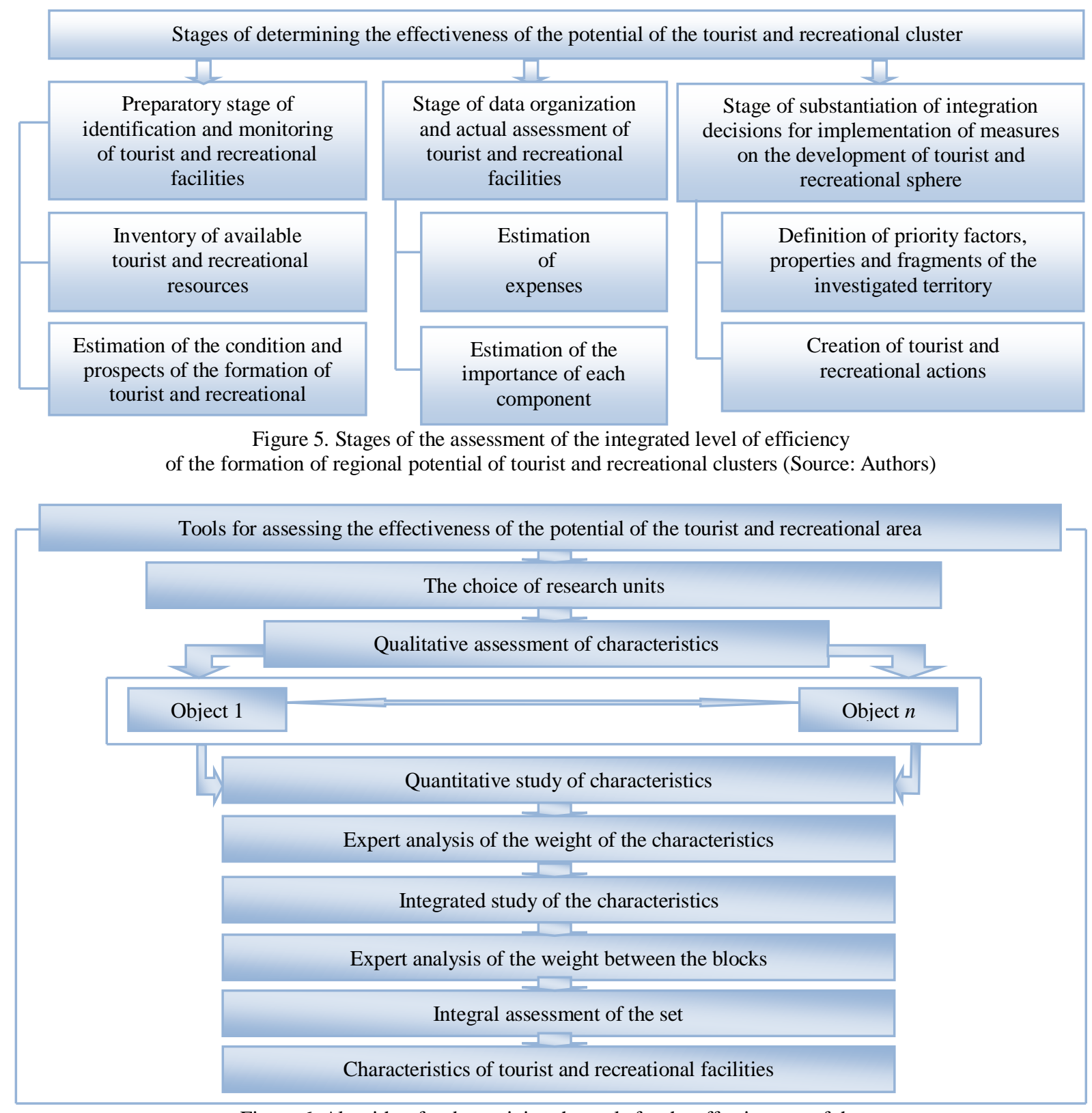

Figure 6. Algorithm for determining the tools for the effectiveness of the formation of the regional potential of tourist and recreational clusters (Source: Authors)

Summarizing the above methodology, we propose to determine the integrated level of efficiency of the formation of the regional potential of tourist and recreational clusters in three stages. At the first (preparatory) stage identification and monitoring of objects is carried out, at the second - data for estimation of objects are organized, at the third - integration decisions for realization of measures for the development of tourist and recreational sphere are substantiated (Figure 5). Comprehensive assessment of the tools for the effectiveness of the formation of the regional potential of tourist and recreational clusters is based on the relationship and interaction of methodological techniques that allow formalizing this process and building an algorithm for its definition (Figure 6).

The attractiveness of the regional potential of tourist and recreational clusters according to a comprehensive expert assessment of the attractiveness of objects in integrated interaction requires the separation of criteria for their evaluation in the field of tourism services and related industries, united by horizontal links. This synergy stimulates the efficiency of regions and individual enterprises, allows to form the effect of innovation, strengthen the intra- and interregional division of labor in the local tourist and recreational system, strengthening individual specialization of members of the regional cluster, due to a range of services focused on the tourism market (Kropinova and Mitrofanova, 2009; Wardana et al., 2018). The activities of the cluster members are focused on the preservation, renovation and use of cultural and historical heritage sites, construction, reconstruction, operation of recreational and tourist industry facilities, facilities for sanatorium treatment, medical rehabilitation and recreation of citizens, as well as for the extraction and use of natural medical resources (Dovbenko, 2007; Shashero, 2011; Casamatta et al., 2021; Baiun, 2021; Ortega-Abente and Ruiz-Flores, 2021).

Thus, the cluster approach is the optimal tool for ensuring the spatial development of European regions. Focus on creating competitive advantages of cluster members, promotes the development and implementation of innovative 
projects in the tourism industry. The main principle of the enterprises included in the cluster is to create an advantage of the cluster through cooperation at the local level in order to compete at the interregional level (Table 2).

In our opinion, the most acceptable approach to understanding the life cycle of a cluster due to changes in its qualitative states (low differentiated, competitive, growth and decline) (Danylyshyn et al., 1999), unfolds three directions of cluster systems - progress, is ogress, regress. Each of these areas is clearly correlated with the level of systemic complexity of tourist and recreational infrastructure in the European spatial field of regional clusters: progress reflects the transition of clusters to a new, higher level of systemic and organizational complexity; regress - to a lower level; is ogress - development of properties and qualities in the current level (Danilchuk et al., 2003).

Table 2. The system of interests of the members of the regional tourist and recreational cluster (Source: Authors)

\begin{tabular}{|l|l|}
\hline $\begin{array}{c}\text { Members of the regional } \\
\text { tourist and recreational cluster }\end{array}$ & \multicolumn{1}{c|}{ Interests of the member of the regional cluster } \\
\hline & $\begin{array}{l}\text { - growth of tax revenues to the budget system; } \\
\text { - the emergence of new forms of interaction with business; } \\
\text { - the emergence of favorable conditions for further diversification of economic growth in the region; } \\
\text { - socio-political significance of the tourist and recreational cluster as an effective form of social obligations } \\
\text { to the population; } \\
\text { - a real opportunity for effective management of socio-economic processes in the tourist and recreational } \\
\text { sphere of the region }\end{array}$ \\
\hline $\begin{array}{l}\text { Entrepreneurial sector of the } \\
\text { region }\end{array}$ & $\begin{array}{l}\text { - the emergence of new economic entities in the business sector of the region; } \\
\text {-growth of competitive positions and business activities of the business sector of the region; } \\
\text { - increasing the social responsibility of the business sector of the region in the field of tourism }\end{array}$ \\
\hline The "third" sector of the region & growth of satisfied demand for the needs of social marketing in the tourist sector of the region. \\
\hline $\begin{array}{l}\text { Household sector } \\
\text { of the region }\end{array}$ & $\begin{array}{l}\text { The growth of satisfied demand for tourist services, both by the population in the region and by the } \\
\text { population outside it }\end{array}$ \\
\hline $\begin{array}{l}\text { All members of the tourist } \\
\text { and recreational cluster } \\
\text { of the region }\end{array}$ & $\begin{array}{l}\text { - ensuring a synergistic effect by creating a tourist and recreational cluster; } \\
\text { - ensuring the effect of scale from reducing costs in the field of tourism and recreation; } \\
\text { - stimulating the creation and effective implementation of innovations; } \\
\text { - attracting foreign investment; } \\
\text { - growth of socio-economic efficiency of tourist and recreational business; } \\
\text { - increasing the efficiency of foreign economic activity of tourist and recreational entities }\end{array}$ \\
\hline
\end{tabular}

It is advisable to supplement the understanding of qualitative changes that occur in clusters with the help of approaches proposed by the categorical-system methodology (Danylyshyn et al., 1999), which is based on the concept of active quality, which determines the development of "object and determines its life cycle". In order to know the object of research within the framework of this methodology, it is important to select the essential components in the object and transform them into "active quality" and "development" of a specific subject area, as well as build qualitative models based on them. A qualitative aspect of this methodology is that it allows characterizing the object as a holistic system that exists in these circumstances, in a given environment, with all its properties and predictable changes. Its qualitative certainty is a stable set of characteristics that create the object of its existence, development, and forms its relationship with other objects and the environment. Development in this context is a variable of the qualities of the object. Categorical quality models allow describing, finding out and predicting the peculiarities of the existence and development of the object under study. Thus, in the "Ordering to goals" model $(O G G)$ the system object consists of three components, each of which corresponds to a separate category (Danylyshyn et al., 1999; Bayighomog and Arasli, 2021; Akbar et al., 2020):

- object that is directly studied as a whole - Object - Quality $(O Q)$;

- object components (elements) - Gratitude $(U q)$;

- the mechanism of unification of parts into a single whole, which corresponds to "Integrative Quality" (IQ), which regulates not only the nature of connections $U q$ with $O Q$, but also interaction $O Q$ with the external environment.

In the model $O G G$ each of the above components of the system is the bearer of a specific goal, which gives it the direction and trajectory of development, determines its life cycle. Interpretation of the tourist and recreational cluster on the basis of a quality model $O G G$ looks like this. A cluster is an integral object $(O Q)$ and by its nature has a systemic organization. The cluster has a goal that determines the direction of its development, it consi sts of members (companies, firms, organizations, institutions), which are its structural elements $(U q)$. All elements of the cluster have personal goals that give them direction. For a cluster, the goals of its individual members are "Sub-goals".

An important characteristic of cluster formation as a system object is the principle, the mechanism of combining parts into a goal: enterprises and firms - in a cluster. This aspect is embodied in the "Super-Goal" of cluster formation. If the nature of "Goal" and "Sub-Goals" $(O Q$ and $U q)$ is acceptable, then the nature of "Super-Goal" (IQ ) is hardly obvious to an observer who is at a certain level of the system. In general, it indicates the presence of new qualities in $O Q$ that indicate that the object is a new level of complexity and makes it possible the transition of $O Q$ to a new stage of development. As a result, it is included in the new environment (Dashchuk, 2012). Three of these aspects of the tourist and recreational cluster of enterprises are reflected in the relevant categories (Table 3).

The life cycle of the object, (tourist-recreational cluster) represents the stages of its active action, as a process that realizes a specific goal and is accompanied by the development of its active quality. Accordingly, the directions of the 
development of the object are closely related to the two triads of categories described above: $O Q-U q-I Q$ and Goal - SubGoal - Super-Goal (Table 4). Thus, progressive development is a change of the system object upwards. In this case, there is a changeIQ, which is reflected in the transformation of the nature of the interaction between the components, which are due to the appearance of new emergent properties in the object, increasing the level of system complexity. This provides it with a transition to a new environment that corresponds to its new, more advanced system of organization. The driving force behind progressive development is the "Super-Goal" of the object. That is, the acquisition of a newIQ one leads to the deployment in the system of special interactions associated with the appearance of emergent properties in it. The transition of the object to a new, more complex environment is accompanied by the emergence of a new "Super-Goal".

Table 3. Tourist and recreational cluster by categories of its active quality (Dashchuk, 2012)

\begin{tabular}{|l|c|c|l|}
\hline \multicolumn{1}{|c|}{ The real object } & Quality category & Goal category & \multicolumn{1}{|c|}{ Characteristics } \\
\hline Cluster of enterprises & $\begin{array}{c}\text { Object - Quality } \\
\text { (OQ) }\end{array}$ & Goal & $\begin{array}{l}\text { Display the qualitative definition } \\
\text { of the object }\end{array}$ \\
\hline $\begin{array}{l}\text { Enterprises - members } \\
\text { of a cluster formation }\end{array}$ & Sub quality (Uq) & Sub-Goal & $\begin{array}{l}\text { Display the qualitative certainty } \\
\text { of a component of an object that } \\
\text { differs from the qualitative } \\
\text { certainty of an integral object }\end{array}$ \\
\hline $\begin{array}{l}\text { Principles of } \\
\text { combining enterprises } \\
\text { into a cluster organism } \\
\text { as a single object }\end{array}$ & $\begin{array}{l}\text { Integrated } \\
\text { quality (IQ) }\end{array}$ & Super-Goal & $\begin{array}{l}\text { Display of emergence (system } \\
\text { qualities) of the object and the } \\
\text { mechanism of interaction of } \\
\text { parts in the whole object }\end{array}$ \\
\hline
\end{tabular}

Table 4. Correspondence of quality categories, goals and vectors of the development (Dashchuk, 2012)

\begin{tabular}{|c|c|c|}
\hline Quality categories & $\begin{array}{c}\text { Goal } \\
\text { categories }\end{array}$ & $\begin{array}{c}\text { Branches of the } \\
\text { development }\end{array}$ \\
\hline $\begin{array}{c}\text { Object - Quality, } \\
\text { (OQ) }\end{array}$ & Goal & Isogress \\
\hline Subquality, (Uq) & Sub-Goals & Regress \\
\hline $\begin{array}{c}\text { Integrated quality, } \\
\text { (IQ) }\end{array}$ & $\begin{array}{c}\text { Super- } \\
\text { Goals }\end{array}$ & Progress \\
\hline
\end{tabular}

In general, the considered model $O G G$ enables systematic use of tools for forming the regional potential of tourist and recreational clusters in the European space. Systematicity determines the innovativeness of the potential and allows obtaining new, non-trivial results in such a subject area as the tourist and recreational industry. By diagnosing the state of existing regional tourist and recreational clusters in the EU and assessing segments of the European tourism market, it is possible to develop measures to improve technological and product innovations that meet the realities of the new methodological paradigm for shaping components and tools to enhance competitiveness and image. The main factors in the use of cluster analysis in market segmentation, in our opinion, is that this analysis is an effective way to classify objects by their characteristics and has proven itself in all spheres of social activity. In a competitive European space, the use of cluster analysis allows to operate with a set of constant factors, according to which, forecasting is based on the method of extrapolation of market trends and indicators. The accuracy and reliability of the forecast depends on the multifactorial and sample size over time. The use of cluster analysis of factors that shape the regional potential of tourist and recreational clusters allows calculating its predicted level of quality in the competitive space of states as a whole.

To do this, it is proposed to calculate the forecast efficiency of the regional potential of tourist and recreational clusters using the growth rate of the final product. The following components were chosen as the main forecasting indicators (Dashchuk, 2012):

$$
P_{y}=\lambda+a_{l} p_{l}+a_{k} p_{k}
$$

where, $P_{y}$ - the growth rate of the final product (national income), in million USD; $y$ - rates of dynamics of visits to tourist sites and reactions in the country, \%; $a_{l}$ - parameter of the degree of labor intensity; $p_{l}-$ growth of labor productivity; $a_{k}$ - parameter of the degree of capital intensity; $p_{k}$ - increase in return on assets.

When setting the problem, it is necessary to consider the features of the competitive environment in the market of tourist and recreational services and its impact on the competitiveness of economic entities in the tourism industry.

\section{RESULTS AND DISCUSSION}

\section{Specifics of the Tourist and Recreational Cluster Development}

Given the general trend of the economic development of EU member states through the creation of tourist and recreational clusters, it is safe to say that the cluster approach in the tourism industry today is becoming increasingly important and widespread, especially in such countries as Spain, Romania and Cyprus. At present, there are 68 tourist and recreational clusters in the EU member states (Figure 7).

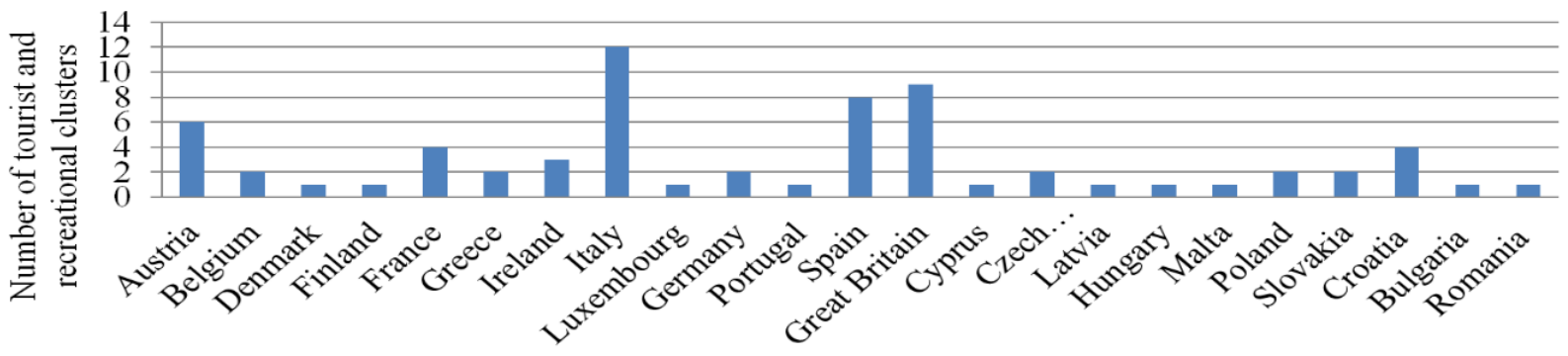

Figure 7. Number of tourist and recreational clusters in EU member states

(UNWTO Tourism Dashboard, 2021; Tourism Satellite Account: Recommended Methodological Framework, 2008; Country Analysis the World Travel \& Tourism Council (WTTC), 2018; Tourist streams, 2020) 
Cluster analysis and audit (ESCA) identified more competitive tourist and recreational clusters in Europe (Table 5). It should be noted that the Western European region is a "testing ground" for testing new ideas in public economic policy, which is based on a cluster approach. Working groups of existing tourist and recreational clusters have been established on the following issues: marketing and branding; tourism product development; issues of personnel policy and improving the quality of labor resources; development of tourist and recreational infrastructure; legislative and regulatory environment (Pankratova, 2021). Within the framework of the development of the tourist and recreational cluster, its main principles are defined: uniqueness; diversification; cultural values; sustainability of the development; integration of the idea of tourism development into the community (state, economy, local community); quality of service; voluntary participation of each member in a functioning cluster (Kliuchenko, 2016; Li et al., 2021). The development of tourist and recreational clusters covers almost all countries of the European Union, both economically developed and Eastern and Central European countries (Lindqvist et al., 2013). From the standpoint of the presence or absence of the relationship between the general Competitiveness Index of EU member states in the field of travel and tourism and sub-indices for the formation of effective regional potential of tourist and recreational clusters, a correlation analysis was performed. Thus, the lines of the general index of competitiveness of countries in the field of travel and tourism by sub-indices of infrastructure and natural and cultural resources have the most similar character. The results of correlation calculations also confirm the presence of a direct relationship between these components.

Infrastructure and its components (correlation coefficient is equal to 0.930235137) and natural and cultural resources (correlation coefficient is equal to 0.891655781) have the greatest impact on the Competitiveness Index of countries in the field of travel and tourism for EU countries (Kuśen, 2010). As for the favorable environment - its impact on the development of the tourist and recreational industry is almost absent (the correlation coefficient is equal to 0.411007181). Public policy and its components in the development of the European tourist and recreational space do not affect the competitiveness of EU member states in the field of travel and tourism (the correlation coefficient is equal to 0.147844926). The result of using hierarchical clustering is a "clustering tree" or dendrogram, i.e. a graph without cycles, built on the proximity matrix. The dendrogram allowed depicting the relationships between objects from a given set. For analysis, 12 components of the Competitiveness Index of EU member states in the field of travel and tourism were selected (90 components). The "full connections" method was chosen as the clustering algorithm, which takes into account that the inclusion of a new object in the cluster occurs only if the distance between the objects is not less than a given level (Table 6).

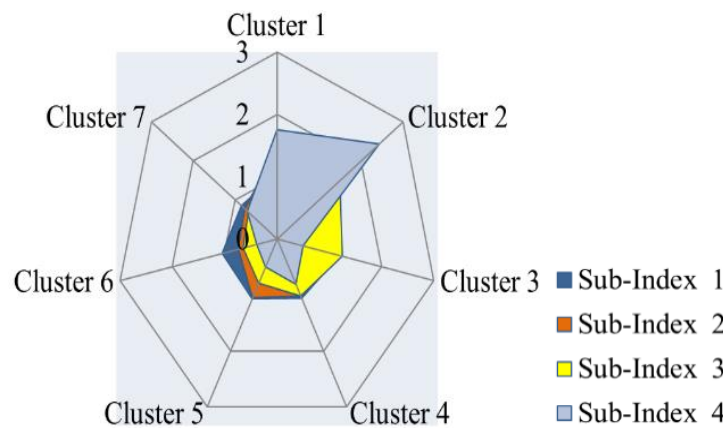

Figure 8. Average values of the features of the regional potential of tourist and recreational clusters of EU member states obtained by the Ward method (Source: Authors)
Table 6. Composition of regional tourist and recreational clusters of EU member states according to the

Ward method (UNWTO Tourism Dashboard, 2021)

\begin{tabular}{|l|c|l|}
\hline $\begin{array}{c}\text { Cluster } \\
\text { number }\end{array}$ & $\begin{array}{c}\text { Number of } \\
\text { objects in } \\
\text { the cluster }\end{array}$ & \multicolumn{1}{|c|}{ The composition of the cluster } \\
\hline Cluster 1 & 3 & Great Britain, the Netherlands, France \\
\hline Cluster 2 & 3 & Spain, Italy, Germany \\
\hline Cluster 3 & 2 & Ireland, Luxembourg \\
\hline Cluster 4 & 6 & Austria, Greece, Denmark, Portugal, Finland, Sweden \\
\hline Cluster 5 & 2 & Cyprus, Malta \\
\hline Cluster 3 & 3 & Estonia, Latvia, Lithuania \\
\hline Cluster 7 & 9 & $\begin{array}{l}\text { Belgium, Bulgaria, Poland, Romania, Slovakia, } \\
\text { Slovenia, Hungary, Croatia, Czech Republic }\end{array}$ \\
\hline
\end{tabular}

In order to characterize each of the selected tourist and recreational clusters and to identify the commonality of EU member states within each of them, the process of grouping in clusters using the Ward method and the K-mean method was used, which allowed to determine different levels of competitiveness in travel and tourism and development potential. Figure 8 shows the composition of tourist and recreational clusters of EU member states grouped by the Ward method. Figure 10 presents the hierarchy of tourist and recreational clusters of EU member states according to the degree of the development of the potential of this industry. The average value is equal to 1.034305 , which exceeds only the first two and the second regional potential of tourist and recreational clusters. In general, the difference between clusters 1-2 and 6-7 is 
insignificant, which indicates a significant degree of similarity in the characteristics of the tourism industry between the countries located in these clusters. The average values of the regional potential of each cluster according to sub-indices allow studying in more detail the level of the development of tourist and recreational infrastructure, availability of resources, favorable conditions of the environment of economic entities of tourism and recreation (Figure 8).

Thus, we can conclude that the level of favorable environment of the regional potential of tourist and recreational clusters of EU member states has the same position. A similar trend is observed in the level of the development of public policy and the creation of favorable conditions in the field of travel and tourism, with the exception of a small priority in the countries of the 1st cluster (UK, Netherlands, France). According to the level of the development of tourist and recreational infrastructure, the countries of clusters 1-3 have an advantage; they are the most developed EU countries: Great Britain, the Netherlands, France, Spain, Italy, Ireland, and Luxembourg. For a more in-depth study, we present the characteristics of each of the selected regional potential of tourist and recreational clusters.

Cluster 1: Great Britain, the Netherlands, France - the countries with the highest level of the development of the tourism industry in Europe. Figure 9 shows the Euclidean distances for the countries of this cluster by the degree of similarity (Figure 9).

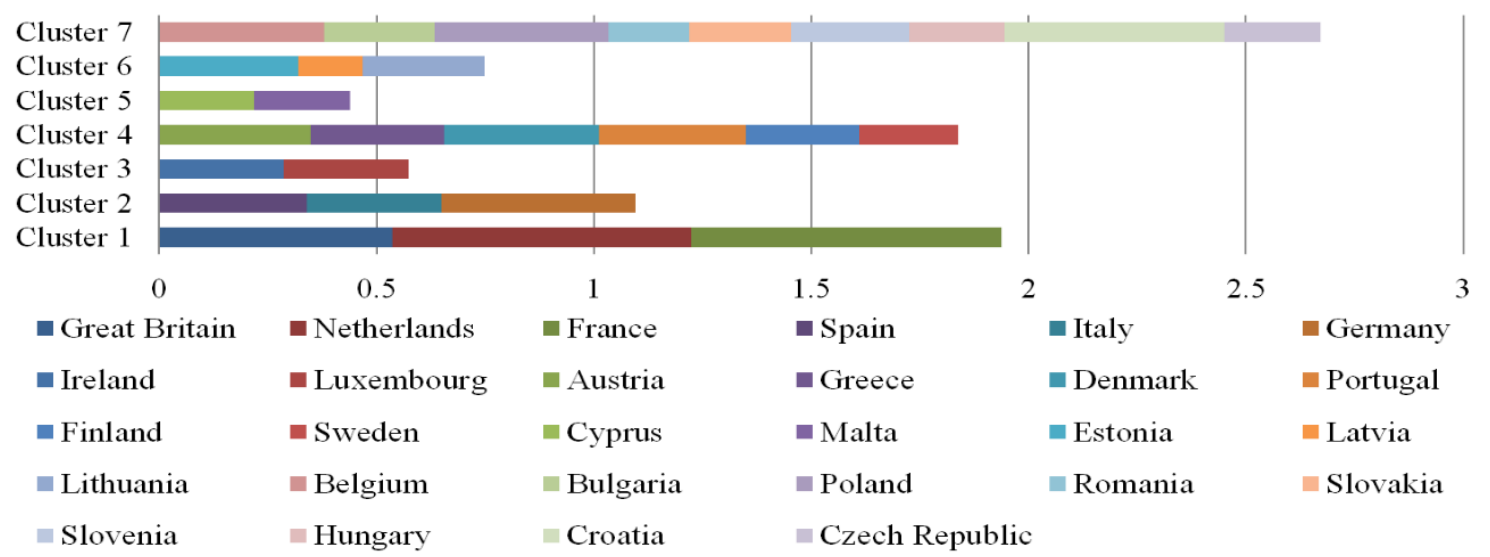

Figure 9. Euclidean distances of regional objects from the center of the potential of tourist and recreational clusters of EU member states (Source: Authors)

The 90 components of regional objects from the center of potential of the tourist and recreational cluster 1 are studied according to their maximum similarity, and according to which there are the greatest differences. The closest to the cluster member countries 1 are such components as: 1.1.8. - Time required to open a business (days); 3.1.5. Density of the network of airports (airports per million of population); 1.1.9. - The cost of starting a business, \% of gross national income per capita; 2.1.2. - Government expenditures for tourism and recreation development (\% in the budget); 3.3.1. - Number of hotel rooms per 100 inhabitants. The smallest similarity between the components of the member countries of this cluster in terms of: 3.1.2. - Domestic passenger-mileage (mln.); 4.2.3. - Number of sports stadiums with a capacity of more than 20000 seats; 2.3.3. - Purchasing power parity (USD); 3.1.3. - International passenger-mileage (mln.); 2.4.10. - Impact of industrial fishing on the marine shelf ecosystem (tons / sq. km).

Cluster 2: Spain, Italy, Germany - countries with a very high level of the development of the tourism industry in Europe. The closest to the cluster member countries are such components as: 2.4.10. - Impact of industrial fishing on the marine shelf ecosystem (tons / sq. km); 3.1.5. - Density of the network of airports (airports per million of population); 3.1.4. - Number of departures (domestic and international) per 1000 of population; 1.4.5. - The practice of hiring and firing employees; 1.2.5. - The rate of homicides per 100000 of population. The smallest similarity between the components of the cluster countries is typical for the indicators: 4.2.5. - Digital demand for cultural and entertainment tourism (estimation based on the analysis of online inquiries about cultural and entertainment institutions of the country according to the established keyword list) (0-100 better); 4.2.1. - Number of cultural objects of the world heritage; 3.1.3. - International passenger-mileage (mln.); 4.2.3. - Number of sports stadiums with a capacity of more than 20000 seats; 3.1.2. - Domestic passenger-mileage (mln.).

Cluster 3: Ireland, Luxembourg - countries with a medium level of the development of the regional potential of the tourist and recreational industry of the European space. The closest to the countries of the cluster are such components as: 3.1.2. - Domestic passenger-mileage (mln.); 4.1.1. - Number of natural world heritage sites; 4.2.2. - Presence of intangible cultural heritage (oral traditions and forms of expression, performing arts, customs, rituals, etc.) (Number of practices and expressions); 4.2.1. - Number of world heritage sites; 2.4.10. - Impact of industrial fishing on the marine shelf ecosystem (tons / sq. km). The slightest similarity between the components of the cluster countries is characteristic of the indicators: 1.1.4. - The effectiveness of the regulatory framework for appealing against government actions or legislation; 1.1.11. - The degree of influence of taxation on investment; 2.2.2. - Openness of the country for bilateral air services agreements (0-38 better); 1.1.6. - The cost of the procedures required for the construction of a warehouse (\% of the cost of construction); 3.1.4. - Number of departures (domestic and international) per 1000 of population.

Cluster 4: Austria, Greece, Denmark, Portugal, Finland, Sweden - countries with a medium level of the development of the regional potential of the tourist and recreational industry of the European space. The closest to the cluster 
countries are such components as: 1.1.9. - The cost of starting a business, $\%$ of gross national income per capita; 2.4 .10 . - Impact of industrial fishing on the marine shelf ecosystem (tons / sq. km); 3.1.3. - International passenger-mileage (mln.); 4.2.2. - Presence of intangible cultural heritage (oral traditions and forms of expression, performing arts, customs, rituals, etc.), (number of practices and expressions); 3.2.5. - Density of railways (km on $100 \mathrm{sq} . \mathrm{m}$ of land). The smallest similarity between the components of the cluster countries is characteristic of the indicators: 2.4.2. - The level of compliance with environmental legislation; 1.5.6. - Subscribers of broadband mobile communication, per 100 residents; 3.3.1. - Number of hotel rooms per 100 inhabitants; 4.1.4. - Digital demand for nature tourism (estimation based on the analysis of online inquiries about natural objects of the country according to the established list of keywords) (0-100 better); 3.1.5. - Density of the network of airports (airports per million of population).

Cluster 5: Cyprus, Malta - countries with a medium level of the development of the regional potential of the tourist and recreational industry of the European space. The closest to the countries of the cluster are such components as: 4.2.2. - The presence of intangible cultural heritage (oral traditions and forms of expression, performing arts, customs, rituals, etc.) (number of practices and expressions); 3.2.5. - Density of railways (km on $100 \mathrm{sq}$. $\mathrm{m}$ of land); 4.2.3. - Number of sports stadiums with a capacity of more than 20000 seats; 3.1.2. - Domestic passenger-mileage (mln.); 1.2.5. - The rate of homicides per 100000 of population. The smallest similarity between the components of the cluster countries is characteristic of the indicators: 2.4.2. - The level of compliance with environmental legislation; 1.5.6. - Subscribers of broadband mobile communication, per 100 residents; 3.3.1. - Number of hotel rooms per 100 inhabitants; 4.1.4. - Digital demand for natural tourism (estimation based on the analysis of online inquiries about natural objects of the country according to the established list of keywords) (0-100 better); 3.1.5. - Density of the network of airports (airports per million of population).

Cluster 6: Estonia Latvia, Lithuania - countries with a medium level of the development of the regional potential of the tourist and recreational industry of the European space. The closest to the countries of the cluster are such components as: 3.1.2. - Domestic passenger-mileage (mln.); 4.2.3. - Number of sports stadiums with a capacity of more than 20000 seats; 4.1.4. Digital demand for nature tourism (estimation based on the analysis of online inquiries about natural objects of the country according to the established list of keywords) (0-100 better); 3.1.3. - International passenger-mileage (mln.); 4.1.1. Number of natural world heritage sites. The smallest similarity between the components of the cluster countries is characteristic of the indicators: 1.3.4. - Number of beds per 10000 of population; 2.3.1. - Taxes and fees at airports (0-100 better); 3.1.5. - Density of the network of airports (airports per million of population); 1.3.5. - Prevalence of HIV (\% of the population aged 15-49 years); 1.2.5. - The rate of homicides per 100000 of population.

Cluster 7: Belgium, Bulgaria, Poland, Romania, Slovakia, Slovenia, Hungary, Croatia, the Czech Republic - countries with a medium level of the development of the regional potential of the tourist and recreational industry of the European space. The closest to the countries of the cluster are such components as: 3.1.2. - Domestic passenger-mileage (mln.); 2.4.10. - Impact of industrial fishing on the marine shelf ecosystem (tons / sq. km); 3.1.3. - International passengermileage (mln.); 3.1.4. - Number of departures (domestic and international) per 1000 of population; 4.2.3. - The number of sports stadiums with a capacity of more than 20000 seats. The smallest similarity between the components of the cluster countries is characteristic of the indicators: 1.1.9. - The cost of starting a business, $\%$ of gross national income per capita; 1.1.8. - Time required to open a business (days); 2.4.4. - Concentration of solid particles in the air (mg / cubic meter); 4.2.2. - Presence of intangible cultural heritage (oral traditions and forms of expression, performing arts, customs, rituals, etc.), (number of practices and expressions); 3.2.5. - Density of railways (km on $100 \mathrm{sq}$. $\mathrm{m}$ of land). Thus, the segmentation of the European tourist and recreational area has identified seven groups of countries (clusters) that have certain similarities in the development of the tourism industry, and, accordingly, have certain requirements for the formation of tourism policy.

\section{Calculating of the Forecast of Tourist and Recreational Clusters Regional Potential}

To calculate the forecast efficiency of the development of the regional potential of tourist and recreational clusters, the growth rate of the national income of each of the EU member states, which is influenced by the tourist and recreational components, was used. To do this, we used formula (16) for the growth rate of the final product. Figure 8 shows the forecast regional potential of tourist and recreational clusters in terms of the growth rate of national income from travel tourism product in EU member states. Thus, in 2021-2023, Malta and Luxembourg will receive the largest national income from tourism and recreation; significant growth is forecast in Finland, Slovenia, Portugal, Latvia, Cyprus, Spain, Ireland, Estonia and the United Kingdom; the lowest income - in such countries as Poland and Greece. In total, in 2021-2023, the regional potential of tourist and recreational clusters in the EU member states will increase the revenue side of the budget by almost 5919.1 billion USD. Thus, Figure 9 traces an even distribution of the regional potential between tourist and recreational clusters (the shares of each cluster are in the range from $9 \%$ to $20 \%$ ).

However, the largest share of income (20\% or 1176 million USD) will be received by the countries of the 7 th cluster (Belgium, Bulgaria, Poland, Romania, Slovakia, Slovenia, Hungary, Croatia, the Czech Republic), the smallest $-9 \%$ or 521 million USD) - countries of the 2nd cluster (Spain, Italy, Germany). This uniformity confirms the objectivity of the segmentation of the European tourist and recreational space and the optimal number of isolated clusters (7).

The study of the growth of national income from the distribution of the regional potential of the tourist and recreational industry on average for each of the clusters confirms the existence of territorial differences between the countries of the tourist space. Thus, the leaders in terms of income in 2021-2023 are the countries of the 5th cluster (Cyprus, Malta); countries of the 3rd and 6th clusters will receive approximately 250 million USD of revenue from the tourist and recreational industry. In the EU member states (clusters 1, 2, 4 and 7) the average growth of national income from the tourist and recreational industry will average 170 million USD. 


\section{CONCLUSIONS}

Thus, the potential of the tourist and recreational industry is undergoing significant transformations under the influence of globalization. These transformations, together with the features common to the world economy (production and consumption of tourist services, management, dissemination of information and technology, the functioning of markets) are carried out on a global scale in Europe; the interconnections and interdependence of the enterprises of the tourist and recreational industry of the countries of the world strengthen and become more complicated; the volume and variety of cross-border movement of goods and services of the industry increases; widespread use of new information technologies have their own specific features. Under the influence of global trends, companies in the tourist and recreational industry are increasingly focusing on international standards of activity; new organizational forms of providing tourist services in the form of transnational corporations (TNCs) and international network associations are being created; international information and communication systems are being formed. Indicators of the regional potential of tourist and recreational clusters in the European space form a global growing internationalization, which is manifested in the deepening of the international division of labor, development and intensification of exports of tourism services, as well as economic cooperation.

The established practice of the tourist and recreational industry provides effective directions for the development of the potential of tourist and recreational services at the interregional level. First, it is a set of situational actions to address some of the most critical problems, taking into account certain legal provisions of current legislation in the field of tourism, the basic requirements of foreign economic activity in the field of services. In this case, the main mechanism for the development of the regional potential of tourist and recreational clusters in the European Union is market selfregulation, and the regulator is the rate of return on invested capital. Secondly, there is a need for regional policy (in the form of normative strategies of medium and short-term programs and the implementation of relevant institutional regulators and tools for building the capacity of tourist and recreational clusters), the mechanism of export of tourism services in EU member states, interregional cooperation on mutually beneficial terms, the movement of tourist flows and the joint tourist product, as well as for public-private partnership in the field of infrastructure creation and promotion of the tourist product on international markets. The formation of the potential of tourist and recreational clusters, marketing and branding of the territory allows complementing the processes of creation and development of regional tourist complexes in cooperation with specialized enterprises in the field of tourism and recreation.

\section{REFERENCES}

Akbar, I., Yang, Z., Mazbayev, O., Seken, A., \& Udahogora, M. (2020). Local residents' participation in tourism at a world heritage site and limitations: A case of aksu-jabagly natural world heritage site, kazakhstan. Geojournal of Tourism and Geosites, 28(1), 35-41. https://doi.org/10.30892/gtg.28103-450

Andrieieva, N.M., \& Polianychko, O.V. (2013). Ecological clusters in the recreational and tourist sphere as a model of regional business development. Economic Forum, 3, 82-87.

Baiun, Yu.V. (2021). Problems of development of the medical industry in Ukraine in the context of the decentralisation reform. Scientific Bulletin of Mukachevo State University. Series “Economics”, 8(1), 86-95. https://doi.org/10.52566/msu-econ.8(1).2021.86-95

Bayighomog, S.W., \& Arasli, H. (2021). Reviving employees' essence of hospitality through spiritual wellbeing, spiritual leadership, and emotional intelligence. Tourism Management, 89. https://doi.org/10.1016/j.tourman.2021.104406

Benedict, M.A., \& McMahon, E.T. (2006). Green infrastructure: Linking landscapes and communities. Washington: Island Press.

Bergman, E.M., \& Feser, E.J. (1999). Industrial and regional clusters: Concepts and comparative applications. Morgantown: Regional Research Institute.

Bondar, O., Tkach, L., Tsytsiura, N., Halahan, O., \& Tryhuba, O. (2021). Analysis of species diversity of forests on the territory of Kharkivska Oblast. Scientific Horizons, 24(1), 77-84. https://doi.org/10.48077/scihor.24(1).2021.77-84

Butler, R. (1980). The concept of a tourist area cycle of evolution: Implications for management of resources. Canadian Geographer, 24, 5-12. https://doi.org/10.1111/j.1541-0064.1980.tb00970.x

Casamatta, G., Giannoni, S., Brunstein, D., \& Jouve, J. (2021). Host type and pricing on airbnb: Seasonality and perceived market power. Tourism Management, 88. https://doi.org/10.1016/j.tourman.2021.104433

Ceballos-Lascurain, H. (1996). Tourism, ecotourism and protected areas: The state of nature-based tourism around the world and guidelines for its development. Cambridge: IUCN Publications. http://dx.doi.org/10.2305/iucn.ch.1996.7.en

Cunha, J. (2005). Tourism cluster competitiveness and sustainability: Proposal for a systemic model to measure the impact of tourism on local development. Brazilian Administration Review, 2(2), 47-62. https://doi.org/10.1590/S1807-76922005000200005

Danilchuk, V.F., Aleynikova, G.M., Bovsunovskaya, A.Ya., \& Golubnichaya, S.N. (2003). Recreational area assessment methodology. Donetsk, DITB.

Danylyshyn, B.D., Dorohuntsov, S.I., \& Mishchenko, V.S. (1999). Natural resource potential of sustainable development of Ukraine. Kyiv: RVPS of Ukraine, National Academy of Sciences of Ukraine.

Dashchuk, Yu.Ye. (2012). Analysis of the components of the recreational potential of the region. Bulletin of the Volodymyr Dahl East Ukrainian National University, 7(178), 71-78.

Dovbenko, O. (2007). Special economic zones of tourist-recreational type: comparative characteristics. Bulletin of Ternopil National Economic University, 2, 135-142.

Frederick, S., Simmons, M., \& Gallagher, M. (2013). The ecological imperative for environmental design and planning. Frontiers in Ecology and the Environment, 11(7), 355-361. https://doi.org/10.1890/130052

Goeldner, C.R., \& Ritchie, J.R. (2009). Tourism: Principles, practices, philosophies. Hoboken: John Wiley \& Sons, Inc.

Haldorai, K., Kim, W.G., \& Garcia, R.L.F. (2021). Top management green commitment and green intellectual capital as enablers of hotel environmental performance: The mediating role of green human resource management. Tourism Management, 88 . https://doi.org/10.1016/j.tourman.2021.104431

Hall, M., \& Page, S.J. (1990). The geography of tourism and recreation: Environment, place and space. New York, Routledge.

Hardin, G. (1968). The tragedy of the commons. Science, 162(3859), 1243-1248. https://doi.org/10.1126/science.162.3859.1243 
Khasawneh, M.S., \& Al-Smadi, H.M. (2018). The changes resulting from globalization in tourism industry and their impact in the development of tourism activity in jordan. Geojournal of Tourism and Geosites, 25(2), 524-542. https://doi.org/:10.30892/gtg.25220-378

Kliuchenko, A.V. (2016). Integral assessment of synergetic effect as an indicator of recreational cluster efficiency. Global and National Economic Problems, 9, 542-546.

Kropinova, E.G., \& Mitrofanova, A.V. (2009). Regional-geographical approach to the concept of "tourist-recreation cluster". I. Kant Bulletin of the Russian State University, 1, 70-75.

Kuśen, E.A. (2010). System of tourism attractions. Tourism, 58(4), 409-424.

Leiper, N. (1979). The framework of tourism. Annals of Tourism Research, 6, 390-407. https://doi.org/10.1016/0160-7383(79)90003-3

Li, H., He, L., \& Yang, J. (2021). Forecasting the medium-term performance of restructured tourism firms with an adaptive integrated predictor. Tourism Management, 88 https://doi.org/10.1016/j.tourman.2021.104436

Lindqvist, G., Solvell, O., \& Ketels, Ch. (2013). The cluster initiative greenbook 2.0. Stockholm: Ivory Tower Publishers.

Machiavelli, A. (2001). Tourist destinations as integrated systems. Tourism Review, 56(3/4), 6-11. https://doi.org/10.1108/eb058361

Nordin, S. (2003). Tourism clustering \& innovation: Path to economic growth and development. Östersund, European Tourism Research Institute.

Ortega-Abente, L., \& Ruiz-Flores, J. (2021). Psychological aspects as the components of academic mobility of medical workers. Scientific Bulletin of Mukachevo State University, Series "Pedagogy and Psychology", 7(2), 54-62. https://doi.org/10.52534/msu-pp.7(2).2021.54-62

Pankratova, V.O. (2021). General principles of law as a source of European Union law. Legal Horizons, 14(2), 111-117. https://doi.org/10.21272/legalhorizons.2021.i14.p111

Selin, S. (1999). Developing a typology of sustainable tourism partnerships. Journal of Sustainable Tourism, 7(3), $260-273$. https://doi.org/10.1080/09669589908667339

Sevenant, M., \& Antrop, M. (2009). Cognitive attributes and aesthetic preferences in assessment and differentiation of landscapes. Journal of Environmental Management, 90, 2889-2899. https://doi.org/10.1016/j.jenvman.2007.10.016

Shashero, A.M. (2011). Methodology for determining the boundaries and composition of the regional ecological network based on the analysis of geographic information bases of land use. Regional Problems of Ukraine: Geographical Analysis and Search for Solutions, 5, 386-391.

Strapchuk, S.I. (2021). Level of ecological and economic diversification: A methodology for assessing the sustainability of agricultural enterprises. Scientific Bulletin of Mukachevo State University, Series “Economics”, 8(2), 101-107. https://doi.org/10.52566/msu-econ.8(2).2021.101-107

Tichaawa, T.M., \& Makoni, L. (2018). Sociodemographic influences on residents' perceptions of tourism development in zimbabwe '. Geojournal of Tourism and Geosites, 22(2), 432-446. https://doi.org/10.30892/gtg.22213-300

Trusova, N.V., Cherniavska, T.A., Pasieka, S.R., Hranovska, V.H., Prystemskyi, O.S., \& Demko, V.S. (2020a). Innovative clustering of the region in the context of increasing competitive positions of the enterprises of the tourist-recreational destination. GeoJournal of Tourism and Geosite, 33(3), 1126-1134. https://doi.org/10.30892/gtg.31326-549

Trusova, N.V., Kyrylov, Yu.Y., Hranovska, V.H., Prystemskyi, O.S., \& Sakun, A.Zh. (2020b). The imperatives of the development of the tourist services market in spatial polarization of the regional tourist system. GeoJournal of Tourism and Geosites, 29(2), 565-582. https://doi.org/10.30892/gtg.29215-490

Trusova, N.V., Tanklevska, N.S., Cherniavska, T.A., Prystemskyi, O.S., Yeremenko, D.V., \& Demko, V.S. (2020c). Financial provision of investment activities of the subjects of the world industry of tourist services. Journal of Environmental Management and Tourism, 4(44), 890-902. https://doi.org/10.14505/jemt.v11.4(44).13

Wardana, I.M., Utama, I.W.M., \& Astawa, I.P. (2018). Model of local population perception in supporting coastal tourism development and planning in bali. Geojournal of Tourism and Geosites, 23(3), 873-880. https://doi.org/10.30892/gtg.23321-335

Zheng, W., Li, M., Lin, Z., \& Zhang, Y. (2021). Leveraging tourist trajectory data for effective destination planning and management: A new heuristic approach. Tourism Management, 89. https://doi.org/10.1016/j.tourman.2021.104437

*** Country Analysis the World Travel \& Tourism Council (WTTC). (2018). https://www.wttc.org/economic-impact/country-analysis/

*** The UNWTO Tourism Dashboard - Insights on key performance indicators for inbound and outbound tourism at the global, regional and national levels. UNWTO Tourism Dashboard. 2021. https://www.unwto.org/unwto-tourism-dashboard

*** Tourism Satellite Account: Recommended Methodological Framework. (2008). United Nations Statistics Division. https://unstats.un.org/unsd/publication/seriesf/seriesf_80rev1e.pdf

*** Tourist streams. (2020). http://www.ukrstat.gov.ua/operativ/operativ2007/tyr/tyr_u/potoki2006_u.htm

Article history: Received: 27.07.2021 Revised: 14.12.2021 Accepted: 21.12.2021 Available online: 31.12 .2021 